\title{
Gut microbial metabolite short-chain fatty acids and obesity
}

\author{
Xuan LI ${ }^{1}$, Yuuki SHIMIZU1 and Ikuo KIMURA ${ }^{1 *}$ \\ ${ }^{1}$ Department of Applied Biological Science, Graduate School of Agriculture, Tokyo University of Agriculture and Technology, Fuchu-shi, \\ Tokyo 183-8509, Japan
}

Received May 8, 2017; Accepted July 23, 2017; Published online in J-STAGE August 25, 2017

\begin{abstract}
Over the past decade, the gut microbiota has emerged as an essential mediator in the pathophysiology of obesity and related metabolic disorders. In this context, the reciprocal interactions of the gut microbiota structure and their metabolite profiles with host metabolism predisposing to a range of pathological conditions (e.g., insulin resistance) related to energy homeostasis have been increasingly discussed in various animal models and human cohorts. Remarkably, as the role of gut microbial metabolites as critical signaling molecules that function through the complementary host receptors has come to be appreciated, tremendous attention has been focused on the proposed diet-gut microbiota-host homeostasis axis, entailing extensive cross-disciplinary efforts in medical, pharmaceutical, and agricultural sciences. This review will discuss the recent advances in understanding the mechanisms whereby the gut microbiota modulates the effects of diet and shapes the host metabolism either towards or away from obesity and related metabolic conditions. In particular, the interactions of short chain fatty acids (SCFAs), a subset of key gut microbial metabolites, with their specific receptors will be reviewed in relation to host energy homeostatic regulation and evaluated for potential as novel therapeutic targets for diet-induced obesity.
\end{abstract}

Key words: SCFA, gut microbiota, energy metabolism, obesity, dietary fiber

\section{INTRODUCTION}

Obesity is a metabolic disorder characterized by disrupted dynamics of energy homeostasis, which depends on the equilibrated dietary intakes and expenditure. The pathogenesis of obesity entails a complex interplay of genetic susceptibility, environmental, and lifestyle factors. The current obesity epidemic, in the context of lifestyle, is plausibly attributed to the growing consumption of westernized, calorie-dense diets of high sugar and saturated fat content. Multiple obesity-associated health consequences have been documented, including increased risk for Type 2 diabetes, cardiovascular disease, and several cancers, contributing to an enormous economic burden and consumption of medical resources [1-3]. In recent years, the gut microbiota has emerged as an integral mediator in diet-induced obesity and hence attracted increasing attention as a potential nutritional and pharmacological target in the management of obesity and related conditions. The gut microbiota is functionally highlighted in its potential to ferment the otherwise nondigestible dietary carbohydrates, produce micronutrients, regulate host energy metabolism, and to reciprocally crosstalk

\footnotetext{
*Corresponding author. Ikuo Kimura, Department of Applied Biological Science, Tokyo University of Agriculture and Technology Graduate School of Agriculture, Fuchu-shi, Tokyo 183-8509, Japan. Tel \& Fax: +81-42-367-5748, E-mail: ikimura@cc.tuat.ac.jp (C) 2017 BMFH Press

This is an open-access article distributed under the terms of the Creative Commons Attribution Non-Commercial No Derivatives (by-nc-nd) License. (CC-BY-NC-ND 4.0: https://creativecommons.org/licenses/by-nc-nd/4.0/)
}

with the immune system [4-6]. Therefore, dysbiosis of the gut microbiota has been implicated in a multitude of metabolic alterations.

This article will review the current perspectives and recent advances with regard to the role of the gut microbiota in shaping host metabolism and modulating the predisposition to obesity. In particular, the mechanisms underlying the impacts of short chain fatty acids (SCFAs), a group of key metabolites of the gut microbiota, on host insulin-mediated glucose homeostasis and adiposity [7-9] will be discussed.

\section{GUT MICROBIOTA STRUCTURE AND OBESITY}

The earliest evidence that substantiated the role of the gut microbiota in modulating host adiposity, as reported by Gordon and coworkers [10], described specifically the observation that germ-free (GF) mice consistently had less body fat than conventionalized SPF (specific pathogen free) ones, albeit with increased food consumption and less energy expenditure. Notably, the gut microbiota of obese mouse models manifested hyperexpression of genes that encode enzymes involved in the fermentation of indigestible polysaccharides and hyperexpression of the genes for lipoprotein lipase (LPL), which functions to hydrolyze lipoprotein triglycerides and to promote the cellular uptake of triglyceride-derived fatty acids [11]. Therefore, it is not surprising that the obese mice exhibited higher levels of fecal acetate and butyrate and less fecal energy loss than their lean counterparts. Gordon and colleagues further revealed that the obesity phenotype was correlated with a shift in the relative abundance of the Bacteroidetes and Firmicutes 
phyla, which collectively constitute more than $90 \%$ of all phylogenetic types of gut microbes, toward Firmicutes dominance [10]. Significantly, implantation of normal and obese microbiotas into the gut of a GF mouse led to increased body fat mass, adding to the evidence that the gut microbiota is a contributing factor to the pathophysiology of obesity in a structure-dependent manner [10].

In the light of these findings, the pathological implications of the gut microbiota in obesity have been increasingly discussed in animal models and human cohorts with the aid of the state-of-the-art genomics and other omics tools (e.g., 16S rRNA gene amplicons and metagenomics), which particularly facilitate characterization of the fastidious gut anaerobes. In human studies, Firmicutes dominance of the gut microbiota was consistently seen in obese subjects, and some diet therapies for obesity have been reported to be effective in modulating the composition of the gut microbiota toward a lean type [12]. Population-based cohort studies conducted in China and European countries indicated that the gut microbiota of type 2 diabetic patients was enriched with non-butyrate-producing species of the genus Clostridium and that there was a decreased abundance of butyrateproducing species; however, no further common patterns of gut microbiota community composition and predicted function were identified, suggesting the significant impacts of distinct lifestyles and long-term diets between the cohorts on the structure and functionality of the gut microbiota [13, 14]. The gut microbiota associated with obese and diabetic phenotypes is also characterized by a reduced abundance of Akkermansia muciniphila, which has been suggested to offer protection against excessive adiposity, inflammation in adipose tissue, metabolic endotoxemia, and insulin resistance [15-18]. A. muciniphila was also found to be less abundant in older subjects and subject fed a high-fat diet [16]. Recent mechanistic studies on the physiological role of $A$. muciniphila indicate that it contributes to the amelioration of insulin resistance by mediating the negative effects of a pro-inflammatory cytokine, interferon-gamma (IFN- $\gamma$ ), on glucose metabolism [17]. On the other hand, the interaction between an outer membrane protein of A. muciniphila and the Toll-like receptor 2 (TLR2)-mediated signaling pathway has emerged as a candidate mechanism that underlies the beneficial role of $A$. muciniphila in host energy metabolism [18].

Roux-en-Y gastric bypass (RYGB) represents a surgical therapy indicated for morbid obesity that enables substantial and sustained weight loss. Recent evidence has emerged that RYGB induces persistent restructuring of the indigenous gut microbiota, which in turn adds to the effectiveness of RYGB in addition to caloric restriction and malabsorption and leads to increased host glucose tolerance and insulin sensitivity. Colonization of non-operated GF mice with the cecal contents of those that had undergone RYGB allowed for significantly reduced host adiposity and body weight, substantiating the role of the gut microbiota in host metabolism and its potential in remediating obesity [19].
Alternations of the gut microbiota have also been indicated to affect host metabolic homeostasis by inducing changes in the serum metabolomic profile, as revealed by recent efforts based upon exhaustive description of the human gut microbiota and serum metabolomics analysis. Specifically, two gut bacterial species, Prevotella copri and Bacteroides vulgatus, were identified to be highly capable of synthesizing branched-chain amino acids (BCAAs), which, along with lipopolysaccharide (LPS), were frequently observed occurring at elevated levels in the serum of insulin-resistant patients [20]. High-fat diet-fed mice colonized with $P$. copri also exhibited insulin resistance and impaired glucose tolerance secondary to an increased serum BCAA level [20]. However, the manner in which the colonization of $P$. copri correlates with host glucose metabolism is inconsistent between studies. For instance, P. copri seemed to promote host glucose metabolism in a separate study using mice that were fed on a high-fiber, low-fat diet [21]. This discrepancy suggests that the interactions between the gut microbiota and host metabolism may be subject to regulations via diverse mechanisms in different disease models or cohorts, which remain to be deciphered.

\section{ANTIBIOTICS AND OBESITY}

Antibiotic exposure is increasingly believed to modify the composition and thus the function of the gut microbiota. For example, a 7-day course of oral administration of vancomycin to obese males was reported to significantly reduce the abundance of the gram-positive bacteria, particularly the Firmicutes, along with the consequent exacerbated host peripheral insulin resistance [22]. In contrast, the use of amoxicillin (a $\beta$-lactam antibiotic), which is normally effective against gram-negative bacteria, exhibited no effect on either the Firmicutes or insulin sensitivity of the host [22]. These observations highlight the role of the gut Firmicutes in mediating obesity-induced insulin resistance.

The mechanisms that underlie the effects of early life antibiotic exposure on host adiposity have also been investigated in relation to the structural and functional alterations of the gut microbiota. For example, Cho et al. identified substantially increased adiposity in the 10-weekold mice that had been exposed to a range of antibiotics at subtherapeutic doses from 4 weeks of age, as compared with those that received no antibiotics. Significantly, a gut microbiota shift towards an increased ratio of the Firmicutes to Bacteroidetes was observed with enriched expression of genes involved in the conversion of carbohydrates into SCFAs. Moreover, elevated levels of gut hormones that are believed to regulate energy metabolism and growth, e.g., glucose-dependent insulinotropic polypeptide (GIP), were concomitantly detected [23]. In human studies, likewise, antibiotic exposure during early infancy (up to 6 months of age) was significantly associated with excessive adiposity at 38 months as characterized by increased body mass index (BMI) scores. Hence it is suggested to account for 
the increased risk of childhood obesity [24]. The differential effects of antibiotic use during and after early infancy are presumably related to the substantial modifications in the gut microbiota associated with the weaning process, which in humans often begins naturally at age 6 months.

\section{GUT MICROBIAL METABOLITES AND OBESITY}

Currently, a growing body of evidence reveals that the molecular interactions between the wide range of metabolites and cell components of the gut microbiota and host metabolism are essentially but differentially involved in the development of obesity, with diverse mechanisms being proposed to account for the related metabolic alternations. For example, specific members of the gut microbiota (e.g., the Clostridium and Eubacterium) contribute to the biotransformation of primary bile acids into their secondary forms within the intestine, whereby the gut microbiota regulates the host bile acid pool size. Secondary bile acids, particularly deoxycholic acid and lithocholic acid, are potent ligands of TGR5, a G-protein coupled receptor (GPCR). The BA-dependent activation of TGR5 stimulates the secretion of an incretin hormone, GLP-1, along with the subsequent release of insulin and hence mediates host energy expenditure [25]. Moreover, gut microbiota metabolism of diet-derived long-chain fatty acids, such as conjugated linoleic acid, gives rise to a multitude of fatty acid species, modulating the host lipid profile and thereby the predisposition to adiposity [26, 27]. Another class of gut microbial products of metabolic significance in the perspective of energy homeostasis is organic acids, among which SCFAs represent a substantial subset afforded by the gut microbial fermentation of dietderived, indigestible poly- and oligosaccharides and the carbohydrates that escape proximal digestion and adsorption. The role of SCFAs as an extra energy source for de novo lipogenesis has been well recognized; besides, accumulating evidence underlines the further involvement of SCFAs in host metabolism via additional mechanisms, as specifically discussed in the following section. Exposure to gut bacterial components has also been implicated in the pathogenesis of obesity and related metabolic conditions via induction of low-grade adipose tissue inflammation and gut microbiota modifications. Flagellin is a structural protein of the bacterial flagellum. Mice deficient in flagellin-recognizing TLR5 were found to exhibit increased adiposity and insulin resistance along with an obese-type gut microbiota. Transplantation of an altered gut microbiota conferred diminished insulin response and an increased susceptibility to obesity in the recipient mice [28]. The TLR5-dependent innate immune signaling hence provides a mechanism for the crosstalk between the gut microbiota composition and products and the immune and metabolic responses of the host individual.

\section{DIETARY FIBER-DERIVED SHORT CHAIN FATTY ACIDS AND OBESITY}

SCFAs, as described above, are a group of important gut microbiota metabolites that are indeed dietary fiber-derived fatty acids with up to six carbon atoms, including primarily acetate, propionate, and butyrate. Although dietary fiber has long been recognized to confer a number of metabolic benefits in the host including a lower risk for developing obesity and diabetes, the molecular mechanisms responsible for these benefits remained elusive until recent years. To date, SCFAs and their receptors have been increasingly appreciated as a pivotal mediator that links diet and the gut microbiota to host physiology by modulating endocrine responses, development and functioning of leukocytes, and the activity of enzymes and transcription factors. Therefore, it will be important to further illuminate the role of SCFA receptors pertaining to the efficacy of dietary interventions and gut microbiota manipulations in the management of obesity and energy metabolic syndrome [6].

GPR41/free fatty acid receptor 3 (FFAR3) and GPR43/ FFAR2 represent two SCFA-specific GPCRs that prevalently occur on gut enteroendocrine cells, adipocytes, and immune cells. Mechanistic studies revealed that activation of GPR41 on enteroendocrine cells stimulated secretion of the gut hormone peptide YY (PYY), which functions to induce satiety and reduce food intake [29], while SCFA-dependent GPR43 signaling was suggested to mediate host insulin sensitivity by promoting GLP-1 secretion [30]. Such molecular mechanisms of SCFA-receptor-mediated metabolic responses were further confirmed in human studies by the finding that administrating propionate to patients with obesity led to enhanced PYY and GLP-1 secretion with significantly reduced adiposity and overall weight gain [31]. The SCFAGPR41/GPR43 interactions in gut epithelial cells have also been suggested to mediate the protective effects of diet and the microbiota by modulating host immune responses. For example, binding of SCFAs to GPR43 on colonic epithelial cells has been reported to alleviate colonic inflammation by augmenting NACHT, LRR and PYD domains-containing protein 3 (NALP3) inflammasome activation [32]. When expressed in the adipose tissue, GPR41 functions to stimulate leptin secretion [33] and GPR43 serves to suppress insulin signaling and adipogenesis [34]. GPR41 was also identified in neurons of the superior cervical ganglion, where it was shown to elevated energy expenditure by increasing sympathetic nervous system activity upon being activated by SCFAs [35].

Recent evidence indicates that butyrate and propionate may also contribute to metabolic health by activating intestinal gluconeogenesis (IGN), which has a dual role in maintaining energy homeostasis: regulation of food intake and enhancement of insulin sensitivity. While butyrate could directly induce the expression of IGN genes via a cAMPdependent mechanism, the IGN activation by propionate was proposed to be mediated through a gut-brain neural circuit that involves GPR41 [36]. Herein, it is noted that 


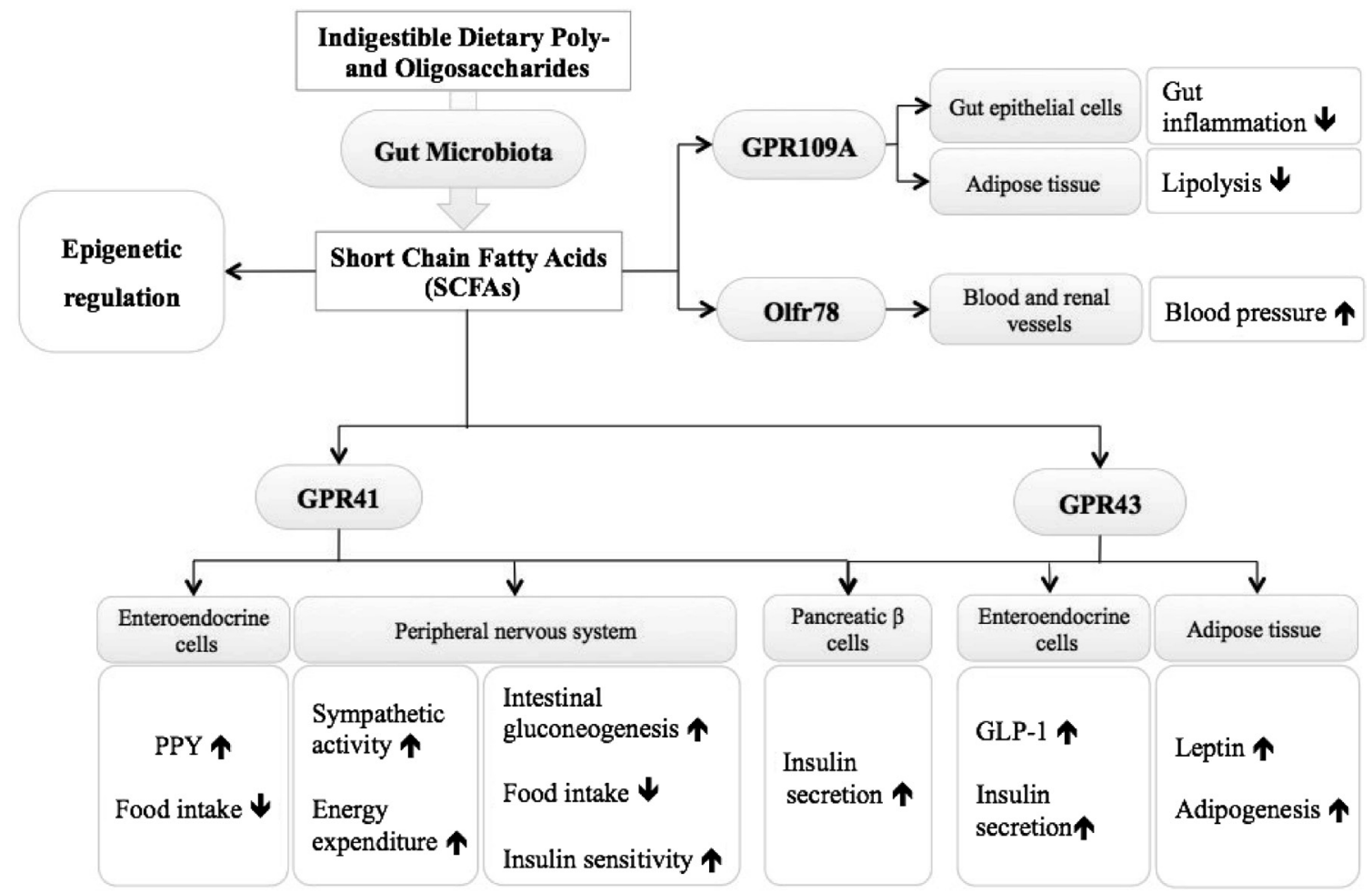

Fig. 1. SCFAs exert multiple effects on host metabolism and physiology via complementary receptors that differentially occur in host tissues.

butyrate, as a potent inhibitor of histone acetyltransferase and deacetylases (HDACs), epigenetically induces the proliferation and differentiation of immune cells [37] and upregulates the adiponectin-mediated AMPK pathway that stimulates mitochondria biogenesis and fatty acid oxidation [38]. In addition, the SCFA-induced GPR41/GPR43 signaling was reported to be capable of directly acting on pancreatic $\beta$ cells to regulate insulin secretion [39-42]. For example, McNeils et al. [40] demonstrated in vitro the enhancement of glucose-stimulated insulin secretion and $\beta$ cell proliferation and gene expression by treating the isolated $\beta$ cells with a GPR43-specific agonist.

More recently, GPR109A was identified as a GPCR specifically activated by niacin, $\beta$-hydroxybutryate, and butyrate. GPR109A, when expressed in colonic epithelial cells, was shown to induce the interleukin (IL)-10- and IL-8-mediated anti-inflammatory response that suppresses colonic inflammation upon binding of the ligand, while in adipose tissue, the ligand-GPR109A interactions likely mediate lipid homeostasis by augmenting the proliferation of local macrophages [43]. SCFAs were further suggested to be associated with blood pressure regulation via an olfactory receptor, Olfr78, which localizes in blood and renal vessels and responds to acetate and propionate [44]. The gut microbiota-derived SCFAs act on and interact with such a multitude of intricately intertwined cellular processes encompassing the nervous, endocrine, and immune systems in a highly tissue-specific manner that deciphering these processes and interactions remains a challenge that requires great effort from multiple disciplines. Simultaneously, however, the growing understanding of SCFAs and their receptors also provides novel therapeutic opportunities for obesity and related health risks by instigating or disrupting SCFA signaling in combination while simultaneously making use of potential as effective epigenetic modulators (Fig. 1).

\section{CONCLUDING REMARKS AND OUTLOOK}

The significant correlations between the structural and metabolic alternations in the gut microbiota and host energy metabolism, indeed, highlight the exceptionally important role of diet in the development and prevention of obesity and other closely related metabolic disorders. Unraveling the complexity of the diet-gut microbiota-host homeostasis axis has led to novel intervention strategies to tackle metabolic disorders including the use of polysaccharide prebiotics coupled with probiotics enriched with SCFA-producing microbes and their extracellular components in functional foods or as dietary supplements. Fecal microbiota transplantation (FMT) from healthy donors also represents a promising treatment for dietinduced obesity through normalization of the gut microflora. In addition, further deciphering the molecular interactions 
between gut metabolites and host signaling pathways will create therapeutic and preventive opportunities for a wide range of metabolic syndromes.

\section{REFERENCES}

1. Kahn SE, Hull RL, Utzschneider KM. 2006. Mechanisms linking obesity to insulin resistance and type 2 diabetes. Nature 444: 840-846. [Medline] [CrossRef]

2. Sanz Y, Santacruz A, Gauffin P. 2010. Gut microbiota in obesity and metabolic disorders. Proc Nutr Soc 69: 434-441. [Medline] [CrossRef]

3. Greenwood HC, Bloom SR, Murphy KG. 2011. Peptides and their potential role in the treatment of diabetes and obesity. Rev Diabet Stud 8: 355-368. [Medline] [CrossRef]

4. Greiner T, Bäckhed F. 2011. Effects of the gut microbiota on obesity and glucose homeostasis. Trends Endocrinol Metab 22: 117-123. [Medline] [CrossRef]

5. Kau AL, Ahern PP, Griffin NW, Goodman AL, Gordon JI. 2011. Human nutrition, the gut microbiome and the immune system. Nature 474: 327-336. [Medline] [CrossRef]

6. Khan MT, Nieuwdorp M, Bäckhed F. 2014. Microbial modulation of insulin sensitivity. Cell Metab 20: 753-760. [Medline] [CrossRef]

7. Inoue D, Tsujimoto G, Kimura I. 2014. Regulation of energy homeostasis by GPR41. Front Endocrinol (Lausanne) 5: 81. [Medline]

8. Kimura I, Inoue D, Hirano K, Tsujimoto G. 2014. The SCFA receptor GPR43 and energy metabolism. Front Endocrinol (Lausanne) 5: 85. [Medline]

9. Kasubuchi M, Hasegawa S, Hiramatsu T, Ichimura A, Kimura I. 2015. Dietary gut microbial metabolites, short-chain fatty acids, and host metabolic regulation Nutrients 7: 2839-2849. [Medline] [CrossRef]

10. Turnbaugh PJ, Ley RE, Mahowald MA, Magrini V, Mardis ER, Gordon JI. 2006. An obesity-associated gut microbiome with increased capacity for energy harvest. Nature 444: 1027-1031. [Medline] [CrossRef]

11. Bäckhed F, Ding H, Wang T, Hooper LV, Koh GY, Nagy A, Semenkovich CF, Gordon JI. 2004. The gut microbiota as an environmental factor that regulates fat storage. Proc Natl Acad Sci USA 101: 15718-15723. [Medline] [CrossRef]

12. Ley RE, Turnbaugh PJ, Klein S, Gordon JI. 2006. Microbial ecology: human gut microbes associated with obesity. Nature 444: 1022-1023. [Medline] [CrossRef]

13. Karlsson FH, Tremaroli V, Nookaew I, Bergström G, Behre CJ, Fagerberg B, Nielsen J, Bäckhed F. 2013. Gut metagenome in European women with normal, impaired and diabetic glucose control. Nature 498: 99-103. [Medline] [CrossRef]

14. Qin J, Li Y, Cai Z, Li S, Zhu J, Zhang F, Liang S, Zhang W, Guan Y, Shen D, Peng Y, Zhang D, Jie Z, Wu W, Qin Y, Xue W, Li J, Han L, Lu D, Wu P, Dai Y, Sun X, Li Z, Tang A, Zhong S, Li X, Chen W, Xu R, Wang M, Feng Q, Gong M, Yu J, Zhang Y, Zhang M, Hansen T, Sanchez G, Raes J, Falony G, Okuda S, Almeida M, LeChatelier E, Renault P, Pons N, Batto JM, Zhang Z, Chen H, Yang R, Zheng W, Li S, Yang H, Wang J, Ehrlich SD, Nielsen R, Pedersen O, Kristiansen K, Wang J. 2012. A metagenome-wide association study of gut microbiota in type 2 diabetes. Nature 490: 55-60. [Medline] [CrossRef]

15. Everard A, Belzer C, Geurts L, Ouwerkerk JP, Druart C, Bindels LB, Guiot Y, Derrien M, Muccioli GG, Delzenne NM, de Vos WM, Cani PD. 2013. Cross-talk between Akkermansia muciniphila and intestinal epithelium controls diet-induced obesity. Proc Natl Acad Sci USA 110: 9066-9071. [Medline] [CrossRef]

16. Schneeberger M, Everard A, Gómez-Valadés AG, Matamoros S, Ramírez S, Delzenne NM, Gomis R, Claret M, Cani PD. 2015. Akkermansia muciniphila inversely correlates with the onset of inflammation, altered adipose tissue metabolism and metabolic disorders during obesity in mice. Sci Rep 5: 16643. [Medline] [CrossRef]

17. Greer RL, Dong X, Moraes ACF, Zielke RA, Fernandes GR, Peremyslova E, Vasquez-Perez S, Schoenborn AA, Gomes EP, Pereira AC, Ferreira SRG, Yao M, Fuss IJ, Strober W, Sikora AE, Taylor GA, Gulati AS, Morgun A, Shulzhenko N. 2016. Akkermansia muciniphila mediates negative effects of IFN $\gamma$ on glucose metabolism. Nat Commun 7: 13329. [Medline] [CrossRef]

18. Plovier H, Everard A, Druart C, Depommier C, Van Hul M, Geurts L, Chilloux J, Ottman N, Duparc T, Lichtenstein L, Myridakis A, Delzenne NM, Klievink J, Bhattacharjee A, van der Ark KCH, Aalvink S, Martinez LO, Dumas ME, Maiter D, Loumaye A, Hermans MP, Thissen JP, Belzer C, de Vos WM, Cani PD. 2017. A purified membrane protein from Akkermansia muciniphila or the pasteurized bacterium improves metabolism in obese and diabetic mice. Nat Med 23: 107-113. [Medline] [CrossRef]

19. Liou AP, Paziuk M, Luevano JM Jr, Machineni S, Turnbaugh PJ, Kaplan LM. 2013. Conserved shifts in the gut microbiota due to gastric bypass reduce host weight and adiposity. Sci Transl Med 5: 178ra41. [Medline] [CrossRef]
20. Pedersen HK, Gudmundsdottir V, Nielsen HB, Hyotylainen T, Nielsen T, Jensen BA, Forslund K, Hildebrand F, Prifti E, Falony G, Le Chatelier E, Levenez F, Doré J, Mattila I, Plichta DR, Pöhö P, Hellgren LI, Arumugam M, Sunagawa S, Vieira-Silva S, Jørgensen T, Holm JB, Trošt K, Kristiansen K, Brix S, Raes J, Wang J, Hansen T, Bork P, Brunak S, Oresic M, Ehrlich SD, Pedersen O, MetaHIT Consortium. 2016. Human gut microbes impact host serum metabolome and insulin sensitivity. Nature 535: 376-381. [Medline] [CrossRef]

21. Kovatcheva-Datchary P, Nilsson A, Akrami R, Lee YS, De Vadder F, Arora T, Hallen A, Martens E, Björck I, Bäckhed F. 2015. Dietary fiber-induced improvement in glucose metabolism is associated with increased abundance of prevotella. Cell Metab 22: 971-982. [Medline] [CrossRef]

22. Vrieze A, Out C, Fuentes S, Jonker L, Reuling I, Kootte RS, van Nood E, Holleman F, Knaapen M, Romijn JA, Soeters MR, Blaak EE, Dallinga-Thie GM, Reijnders D, Ackermans MT, Serlie MJ, Knop FK, Holst JJ, van der Ley C, Kema IP, Zoetendal EG, de Vos WM, Hoekstra JB, Stroes ES, Groen AK, Nieuwdorp M. 2014. Impact of oral vancomycin on gut microbiota, bile acid metabolism, and insulin sensitivity. J Hepatol 60: 824-831. [Medline] [CrossRef]

23. Cho I, Yamanishi S, Cox L, Methé BA, Zavadil J, Li K, Gao Z, Mahana D, Raju K, Teitler I, Li H, Alekseyenko AV, Blaser MJ. 2012. Antibiotics in early life alter the murine colonic microbiome and adiposity. Nature 488: 621-626. [Medline] [CrossRef]

24. Trasande L, Blustein J, Liu M, Corwin E, Cox LM, Blaser MJ. 2013. Infant antibiotic exposures and early-life body mass. Int J Obes 37: 16-23. [Medline] [CrossRef]

25. Thomas C, Gioiello A, Noriega L, Strehle A, Oury J, Rizzo G, Macchiarulo A, Yamamoto H, Mataki C, Pruzanski M, Pellicciari R, Auwerx J, Schoonjans K. 2009. TGR5-mediated bile acid sensing controls glucose homeostasis. Cell Metab 10: 167-177. [Medline] [CrossRef]

26. Kishino S, Takeuchi M, Park SB, Hirata A, Kitamura N, Kunisawa J, Kiyono H, Iwamoto R, Isobe Y, Arita M, Arai H, Ueda K, Shima J, Takahashi S, Yokozeki K, Shimizu S, Ogawa J. 2013. Polyunsaturated fatty acid saturation by gut lactic acid bacteria affecting host lipid composition. Proc Natl Acad Sci USA 110: 17808-17813. [Medline] [CrossRef]

27. Miyamoto J, Mizukure T, Park SB, Kishino S, Kimura I, Hirano K, Bergamo P Rossi M, Suzuki T, Arita M, Ogawa J, Tanabe S. 2015. A gut microbial metabolite of linoleic acid, 10-hydroxy-cis-12-octadecenoic acid, ameliorates intestinal epithelial barrier impairment partially via GPR40-MEK-ERK pathway. J Biol Chem 290: 2902-2918. [Medline] [CrossRef]

28. Vijay-Kumar M, Aitken JD, Carvalho FA, Cullender TC, Mwangi S, Srinivasan S, Sitaraman SV, Knight R, Ley RE, Gewirtz AT. 2010. Metabolic syndrome and altered gut microbiota in mice lacking Toll-like receptor 5. Science 328: 228-231. [Medline] [CrossRef]

29. Samuel BS, Shaito A, Motoike T, Rey FE, Backhed F, Manchester JK, Hammer RE, Williams SC, Crowley J, Yanagisawa M, Gordon JI. 2008. Effects of the gut microbiota on host adiposity are modulated by the short-chain fatty-acid binding G protein-coupled receptor, Gpr41. Proc Natl Acad Sci USA 105: 16767-16772. [Medline] [CrossRef]

30. Tolhurst G, Heffron H, Lam YS, Parker HE, Habib AM, Diakogiannaki E, Cameron J, Grosse J, Reimann F, Gribble FM. 2012. Short-chain fatty acids stimulate glucagon-like peptide-1 secretion via the G-protein-coupled receptor FFAR2. Diabetes 61: 364-371. [Medline] [CrossRef]

31. Chambers ES, Viardot A, Psichas A, Morrison DJ, Murphy KG, Zac-Varghese SE, MacDougall K, Preston T, Tedford C, Finlayson GS, Blundell JE, Bell JD, Thomas EL, Mt-Isa S, Ashby D, Gibson GR, Kolida S, Dhillo WS, Bloom SR, Morley W, Clegg S, Frost G. 2015. Effects of targeted delivery of propionate to the human colon on appetite regulation, body weight maintenance and adiposity in overweight adults. Gut 64: 1744-1754. [Medline] [CrossRef]

32. Macia L, Tan J, Vieira AT, Leach K, Stanley D, Luong S, Maruya M, Ian McKenzie C, Hijikata A, Wong C, Binge L, Thorburn AN, Chevalier N, Ang C, Marino E, Robert R, Offermanns S, Teixeira MM, Moore RJ, Flavell RA, Fagarasan S, Mackay CR. 2015. Metabolite-sensing receptors GPR43 and GPR109A facilitate dietary fibre-induced gut homeostasis through regulation of the inflammasome. Nat Commun 6: 6734. [Medline] [CrossRef]

33. Zaibi MS, Stocker CJ, O'Dowd J, Davies A, Bellahcene M, Cawthorne MA, Brown AJH, Smith DM, Arch JRS. 2010. Roles of GPR41 and GPR43 in leptin secretory responses of murine adipocytes to short chain fatty acids. FEBS Lett 584: 2381-2386. [Medline] [CrossRef]

34. Kimura I, Ozawa K, Inoue D, Imamura T, Kimura K, Maeda T, Terasawa K, Kashihara D, Hirano K, Tani T, Takahashi T, Miyauchi S, Shioi G, Inoue H, Tsujimoto G. 2013. The gut microbiota suppresses insulin-mediated fat accumulation via the short-chain fatty acid receptor GPR43. Nat Commun 4: 
1829. [Medline] [CrossRef]

35. Kimura I, Inoue D, Maeda T, Hara T, Ichimura A, Miyauchi S, Kobayashi M, Hirasawa A, Tsujimoto G. 2011. Short-chain fatty acids and ketones directly regulate sympathetic nervous system via $\mathrm{G}$ protein-coupled receptor 41 (GPR41). Proc Natl Acad Sci USA 108: 8030-8035. [Medline] [CrossRef]

36. De Vadder F, Kovatcheva-Datchary P, Goncalves D, Vinera J, Zitoun C, Duchampt A, Bäckhed F, Mithieux G. 2014. Microbiota-generated metabolites promote metabolic benefits via gut-brain neural circuits. Cell 156: 84-96. [Medline] [CrossRef]

37. Furusawa Y, Obata Y, Fukuda S, Endo TA, Nakato G, Takahashi D, Nakanishi Y, Uetake C, Kato K, Kato T, Takahashi M, Fukuda NN, Murakami S, Miyauchi E, Hino S, Atarashi K, Onawa S, Fujimura Y, Lockett T, Clarke JM, Topping DL, Tomita M, Hori S, Ohara O, Morita T, Koseki H, Kikuchi J, Honda K, Hase K, Ohno H. 2013. Commensal microbe-derived butyrate induces the differentiation of colonic regulatory T cells. Nature 504: 446-450. [Medline] [CrossRef]

38. Hong J, Jia Y, Pan S, Jia L, Li H, Han Z, Cai D, Zhao R. 2016. Butyrate alleviates high fat diet-induced obesity through activation of adiponectin-mediated pathway and stimulation of mitochondrial function in the skeletal muscle of mice. Oncotarget 7: 56071-56082. [Medline] [CrossRef]

39. Tang C, Ahmed K, Gille A, Lu S, Gröne HJ, Tunaru S, Offermanns S. 2015. Loss of FFA 2 and FFA 3 increases insulin secretion and improves glucose tolerance in type 2 diabetes. Nat Med 21: 173-177. [Medline] [CrossRef]
40. McNelis JC, Lee YS, Mayoral R, van der Kant R, Johnson AMF, Wollam J, Olefsky JM. 2015. GPR43 potentiates $\beta$-cell function in obesity. Diabetes 64 : 3203-3217. [Medline] [CrossRef]

41. Veprik A, Laufer D, Weiss S, Rubins N, Walker MD. 2016. GPR41 modulates insulin secretion and gene expression in pancreatic $\beta$-cells and modifies metabolic homeostasis in fed and fasting states. FASEB J 30: 3860-3869. [Medline] [CrossRef]

42. Priyadarshini M, Villa SR, Fuller M, Wicksteed B, Mackay CR, Alquier T, Poitout V, Mancebo H, Mirmira RG, Gilchrist A, Layden BT. 2015. An acetate-specific GPCR, FFAR2, regulates insulin secretion. Mol Endocrinol 29: 1055-1066. [Medline] [CrossRef]

43. Singh N, Gurav A, Sivaprakasam S, Brady E, Padia R, Shi H, Thangaraju M, Prasad PD, Manicassamy S, Munn DH, Lee JR, Offermanns S, Ganapathy V. 2014. Activation of Gpr109a, receptor for niacin and the commensal metabolite butyrate, suppresses colonic inflammation and carcinogenesis. Immunity 40 128-139. [Medline] [CrossRef]

44. Pluznick JL, Protzko RJ, Gevorgyan H, Peterlin Z, Sipos A, Han J, Brunet I, Wan LX, Rey F, Wang T, Firestein SJ, Yanagisawa M, Gordon JI, Eichmann A, Peti-Peterdi J, Caplan MJ. 2013. Olfactory receptor responding to gut microbiotaderived signals plays a role in renin secretion and blood pressure regulation. Proc Natl Acad Sci USA 110: 4410-4415. [Medline] [CrossRef] 